\title{
Allometric Dynamics in Branch Growth of Crape Myrtle
}

\author{
Xiongwen Chen $^{1}$ \\ ${ }^{1}$ Department of Biological \& Environmental Sciences, 139 ARC, Alabama A \& M University, Normal, AL, USA \\ Correspondence: Xiongwen Chen Department of Biological \& Environmental Sciences, 139 ARC, Alabama A \& \\ M University, Normal, AL, USA. Tel: 256-372-4231. E-mail: xiongwen.chen@ aamu.edu
}

Received: February 18, 2017

Accepted: March 21, 2017 Online Published: March 29, 2017

doi:10.5539/jps.v6n2p28

URL: https://doi.org/10.5539/jps.v6n2p28

\begin{abstract}
Tree branches provide multiple functions in tree growth. It is necessary to study the allometric patterns of branches in order to understand some quantitative perspectives in tree growth. In this study, branches of seven crape myrtle trees (Lagerstroemia indica) were studied to examine allometric relationships in different times. The results indicated that the total basal area of branches at one order was far more than it at the next lower order (branches far from trunks). The scaling exponents of frequency distribution in both branch length and diameter decreased from above 1.0 in May to 0.1 in November as branches grew. The entropy of branch length and diameter both decreased at the beginning and then increased for all trees during the growing season. The observed entropy was always less than the maximum entropy. The average slenderness of branches was close to 20 for all trees. There were higher fluctuations in the slenderness within small or short branches (diameter less than $10 \mathrm{~mm}$ or length less than $100 \mathrm{~cm}$ ). The scaling exponents between branch radius and length were concentrated at 1.0 for most trees. The correlation between the branch diameters of $1^{\text {st }}$ order and the number of branches at $2^{\text {nd }}$ order was not significant. The general trend and deviations in allometric relationships may help to understand the complexity in tree branch development.
\end{abstract}

Keywords: Alabama, branch order, entropy, scaling exponent, slenderness

\section{Introduction}

Studying the patterns of branch growth is important to understand tree growth. Changes to tree morphology, such as changes with age and crowding, have been previously studied in forestry with an emphasis on timber (Raulier et al., 1996). Tree branches provide multiple functions during tree growth, such as light interception, canopy photosynthesis, water and nutrient transportation, space filling, and biomechanical tolerance of wind or rain (snow) loading (Küppers, 1989; Skatter \& Kucera, 2000; Nishimura 2005). Tree branching is influenced by many biological and environmental processes in trees, such as photosynthesis and drought. Analysis of branch development is an essential procedure for improving our knowledge of tree survival and growth strategies. Multiple parameters including branch diameter, length, intensity, angle, and age have been incorporated into analyses of branch growth because they all affect branch growth and branching patterns (Remphrey \& Powell, 1984; Remphrey \& Davidson, 1992; Takenaka, 2000; Taugourdeau et al., 2012).

The quantitative relationship in tree branching, which means allometric patterns of branches, is one important aspect in studying tree branching because it can help to understand tree growth and make prediction in the similar species (or groups). For example, the sum of the cross sections of branches at next level (or branch order) is the same as that of the parent branches which are close to trunks (Richter, 1970); fractal geometry (Mandelbrot, 1978) could be used to describe iterative branching systems or the similarity of branching patterns. It was suggested that branches of each tree-shape organism (e.g., trees, heart systems and etc) follow a power law with an invariant exponent (e.g., 3/4) because all tree species share an optimal design of the vascular system which is related to plant physiology (Enquist et al., 1999, West et al., 1999). Sperry et al. (2008) indicated that tree crowns do not exhibit the most efficient hydraulic architecture due to the limitations of mechanical safety. Allometric relationships that describe branch growth are often studied through $\log -\log$ relationship. There are three similar models that describe growth patterns in trees as power law functions $\left(L=a R^{b}\right.$, here $L$ is branch length, $R$ is branch or stem radius). When the $b$ values are close to $1.0,0.67$, or 0.5 , the power function is called geometric similarity model, elastic similarity model and static stress similarity model, respectively (McMahon, 1975). Previous researchers have found different outcomes for allometric patterns in different tree species (e.g., McMahon, 1975; King, 1986; Niklas, 1995; Osunkoya et al., 2007). Chen \& Burton (2010) found that loblolly 
pines and sugar maples followed the same power law in individual trees and also at species level. Most of the red maple individuals did not follow a power law although they followed a power law at the species level. There is a suggestion that an allometric relationship might change from the elastic model to the stress similarity model due to species and other factors (Niklas \& Spatz, 2000). Smaller branches fit a curvilinear pattern in Quercus alba L. and Acer saccharinum L. until they reach approximately 3,000 $\mathrm{mm}$ where they are best modeled with elastic similarity model (McMahon \& Kronauer, 1976). Bertram (1989) found that slenderness (branch length/branch basal radius) increased in small branches (radius $\leq 10 \mathrm{~mm}$ ) while decreased in large branches (radius $\geq 10$ $\mathrm{mm}$ ). Here a hypothesis could be derived that allometric relationships in branches may change with tree growth.

Furthermore, all the branches of a tree are formed as a self-organized network. The tree branch network should follow the principle of maximum entropy (MaxEnt), which means the probability distribution of branches best represents the current state and reaches the largest entropy (e.g., Jaynes, 1957). MaxEnt has been frequently used in ecology (Harte, 2011). It could be assumed that tree branches follow MaxEnt during their growth. It is hard to test these hypotheses on large trees due to the difficulty of accessing and measuring branches. However, it is possible to measure all branches on crape myrtle in the southern region due to its unique management. Crape myrtle is usually coppiced in winter, allowing easy access to its branches. It is possible to use crape myrtle trees as a case study to test the above hypotheses related to allometric patterns of tree branches. The specific objectives include (i) whether the distribution of branch length and diameter follows similar power laws for individual trees; whether the scaling exponents of these power laws are the same; (ii) whether branch slenderness stays the same during the growth of individual trees; (iii) whether MaxEnt exists in branch length or diameter during a growing period. The results of this study will provide better understanding of tree growth, especially on the quantitative relationships of tree growth.

\section{Materials and Methods}

Crape myrtle (Lagerstroemia indica) is a popular ornamental plant in the south because of their showy flowers and aesthetic display. The species is most often found as a multiple-trunked tree or shrub. Usually all branches on crape myrtle are cut (pruned) in winter or early spring and bloom on new growth from the stems (Fig. 1). This is a common tree management activity in the southern region. Due to this unique practice where all branches are cut in winter, it provides convenience for us to measure each branch multiple times during the growing period. In this study, seven trees of crape myrtle at the same location on the campus of Alabama A \& M University were selected. The trees at the same location were chosen because we want to limit the influence from environmental factors related to locations. Seven trees were selected because of the considerable amount of measurements in branches with tree growth. All branches were cut in the winter of 2015. The trunks were approximately $1.3 \mathrm{~m}$ in height. The tree branches started to grow near the end of April in 2016. The measurements, which include the branch length $(\mathrm{cm})$ and diameter at branch base $(\mathrm{mm})$, were conducted in May, July and October, 2016. The branch order $\left(1^{\text {st }}, 2\right.$ nd, 3 rd $)$ for each branch was determined in October. The $1^{\text {st }}$ order branches are those directly growing from trunks.

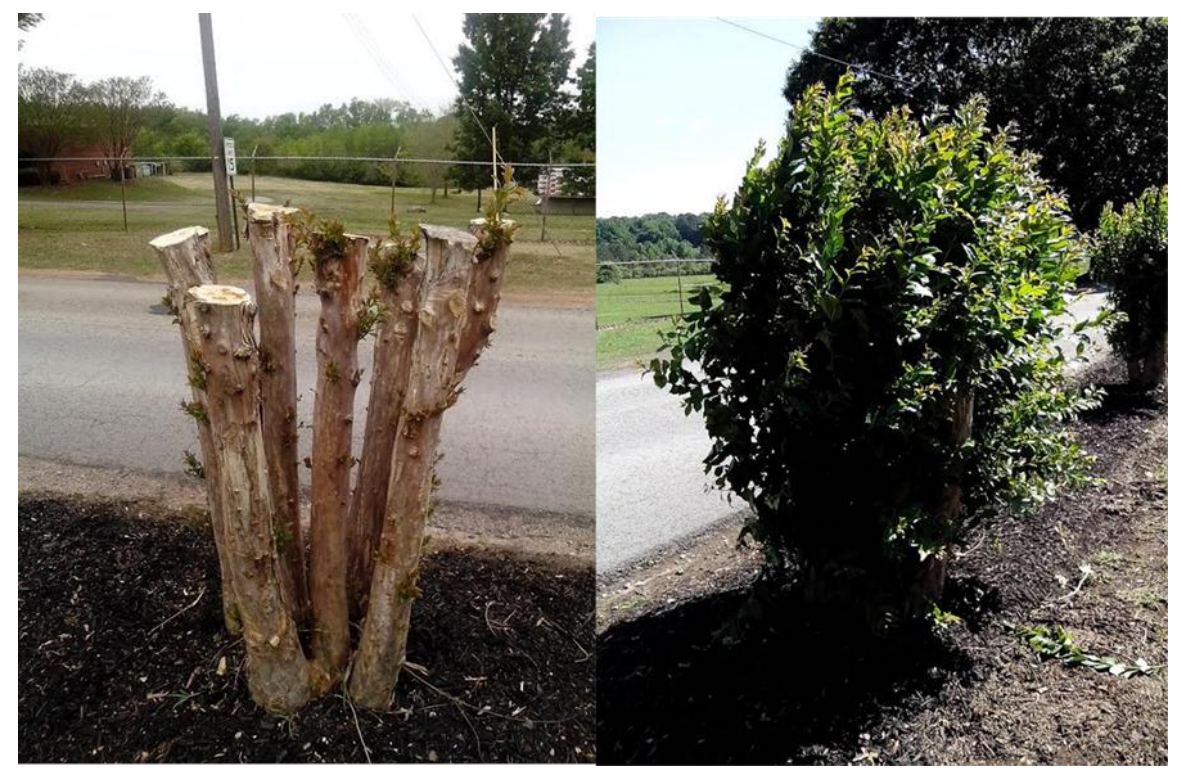

Figure 1. Crape myrtle in early spring and summer 
The lengths of all branches at each tree were sorted based on the length increase of every $20 \mathrm{~cm}$. For example, branches with a maximal length of $120 \mathrm{~cm}$ have the following length categories: $\leq 20, \leq 40, \leq 60, \ldots, \leq 120$. The number of branches within each length category was counted. For each tree, a table was made showing the cumulative percentage for the number of branches within each length based on a method provided by White et al. (2008). Finally, a figure with the logarithm of diameter and logarithm of accumulated frequency was used. Similar method was used for branch diameters.

The exponent of branch length and diameter ( $L \propto D$ ) was estimated through $\log _{10}-\log _{10}$ transformation. A figure with the $\log _{10}$ of $L$ and the $\log _{10}$ of $D$ was produced for this study. To be consistent with current literature on the estimation of allometric relationships, a reduced major axis (RMA) of regression analysis Model Type II was used to determine scaling exponents ( $\alpha$ RMA). ANOVA of SAS software (Cary, NC) was used to compare statistical difference at $\alpha=0.05$ level.

The entropy $(E)$ of branch length or diameter was calculated as the followings:

$$
E=\sum p_{i} \log p_{i}
$$

where $p_{\mathrm{i}}$ is the percentage of any one branch in the total length or diameter (branch length (diameter) of any one branch / total branch length (diameter)) for each tree at the measuring time $i$. It is also called information entropy. The MaxEnt was estimated with the assumption that all $p_{\mathrm{i}}$ values are the same.

\section{Results}

The first tree (Tree ID 1) grew fast and the last tree (Tree ID 7) grew slowly based on the total branch length and basal area (Fig. 2). The total basal area of branches at one level were far more than it at the next lower level, even at each trunk, such as for Tree 1 and 2 (Table 1). The pipe model was not followed.
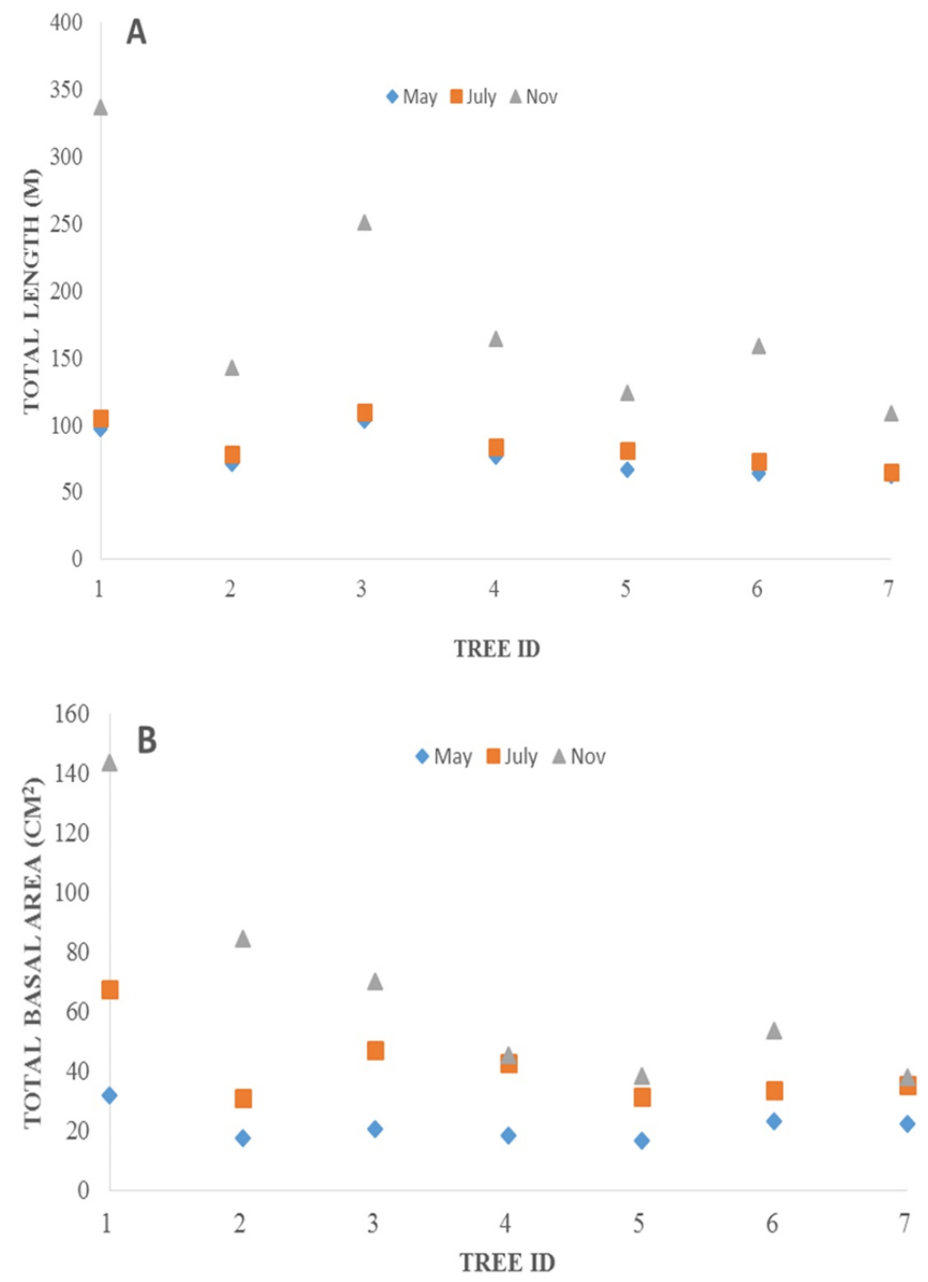

Figure 2. Dynamics of total branch length (A) and basal area (B) for each tree 
Table 1. Total basal area $\left(\mathrm{cm}^{2}\right)$ of branches at different levels (orders) for some trees

\begin{tabular}{lllllll}
\hline Tree ID & Trunk \# & Trunk section area & Level 1 & Level 2 & Level 3 & Level 4 \\
\hline 1 & I & 29.4 & 14.7 & 6.1 & 4.1 & 0.7 \\
& II & 24.0 & 9.6 & 3.6 & 1.2 & 0.1 \\
& III & 36.0 & 28.2 & 20.4 & 17.8 & 0.8 \\
& IV & 33.7 & 20.8 & 11.4 & 7.2 & 1.1 \\
& V & 28.8 & 13.3 & 6.9 & 4.6 & 0.8 \\
\hline 2 & I & 21.2 & 10.6 & 4.1 & 1.8 & 0 \\
& II & 21.5 & 7.5 & 2.9 & 0.6 & 0 \\
& III & 25.3 & 12.0 & 5.8 & 1.9 & 0.5 \\
& IV & 15.7 & 7.0 & 1.3 & 0.4 & 0 \\
& V & 19.4 & 5.0 & 3.6 & 1.4 & 0 \\
\hline
\end{tabular}

The scaling exponents of the frequency distribution for branch length in each tree decreased with branch growth from above 1.0 in May to 0.1 in November (Table 2). The scaling exponents of the frequency distribution for branch diameter decreased with branch growth for Tree 2 and 3 (Table 2), but some trees (Tree 1, 4, 5 and 6) the scaling exponents increased in July and then decreased in November.

Table 2. Scaling exponents of the frequency distribution for branch length and diameter at different times in seven trees

\begin{tabular}{lllllll}
\hline \multirow{2}{*}{ Tree ID } & \multicolumn{2}{c}{ May } & \multicolumn{2}{c}{ July } & \multicolumn{2}{c}{ November } \\
\cline { 2 - 7 } & Length & Diameter & Length & Diameter & Length & Diameter \\
\hline 1 & 1.1066 & 1.0327 & 1.1045 & 1.1813 & 0.0891 & 0.0893 \\
2 & 1.3045 & 0.9378 & 0.5960 & 0.4982 & 0.1378 & 0.1327 \\
3 & 1.2697 & 1.0207 & 0.7273 & 0.8201 & 0.1215 & 0.1231 \\
4 & 1.1520 & 0.4334 & 0.7741 & 0.7414 & 0.1956 & 0.6151 \\
5 & 1.4699 & 0.7725 & 0.5224 & 1.3403 & 0.1285 & 0.6497 \\
6 & 1.1277 & 0.8198 & 0.9408 & 1.0611 & 0.3434 & 0.4838 \\
7 & 1.0570 & 1.0179 & 0.7129 & 0.6033 & 0.1677 & 0.7626 \\
\hline
\end{tabular}

The entropy of branch length was very similar with the entropy of branch diameter for each tree (Table 3). Both entropy values decreased in July and increased in November for all trees. At each time the entropy values of branch length and diameter were less than the MaxEnt.

Table 3. Entropy of branch length and diameter at different times for seven trees

\begin{tabular}{llllllllll}
\hline \multirow{2}{*}{ Tree ID } & \multicolumn{3}{c}{ May, 2016 } & \multicolumn{3}{c}{ July, 2016 } & \multicolumn{2}{c}{ November, 2016 } \\
\cline { 2 - 9 } & Length & Diameter & MaxEnt & Length & Diameter & MaxEnt & Length & Diameter & MaxEnt \\
\hline 1 & 2.36 & 2.37 & 2.41 & 1.99 & 2.00 & 2.07 & 2.94 & 2.99 & 3.20 \\
2 & 2.22 & 2.22 & 2.26 & 2.04 & 2.03 & 2.14 & 2.43 & 2.46 & 2.67 \\
3 & 2.39 & 2.30 & 2.34 & 1.92 & 1.94 & 2.04 & 2.69 & 2.41 & 2.93 \\
4 & 2.26 & 2.25 & 2.44 & 2.11 & 1.97 & 2.04 & 2.56 & 2.60 & 2.71 \\
5 & 2.17 & 2.17 & 2.20 & 1.80 & 1.85 & 1.91 & 2.42 & 2.45 & 2.68 \\
6 & 2.19 & 2.08 & 2.24 & 1.97 & 1.99 & 2.05 & 1.89 & 1.92 & 2.06 \\
7 & 2.21 & 2.15 & 2.26 & 1.99 & 2.00 & 2.09 & 2.34 & 2.41 & 2.56 \\
\hline
\end{tabular}

The average slenderness of branches was always close to 20 with tree growth for each tree. There was no significant difference in average slenderness among trees due to variances (Fig. 3). Generally there were higher fluctuations in slenderness for the small branches (diameter less than $10 \mathrm{~mm}$ ) than the bigger ones (Fig. 4A). Similar results were observed for the slenderness along branch length (Fig 4B). There were higher fluctuations in slenderness for the short branches (length less than $100 \mathrm{~cm}$ ) in comparison to the longer branches. 


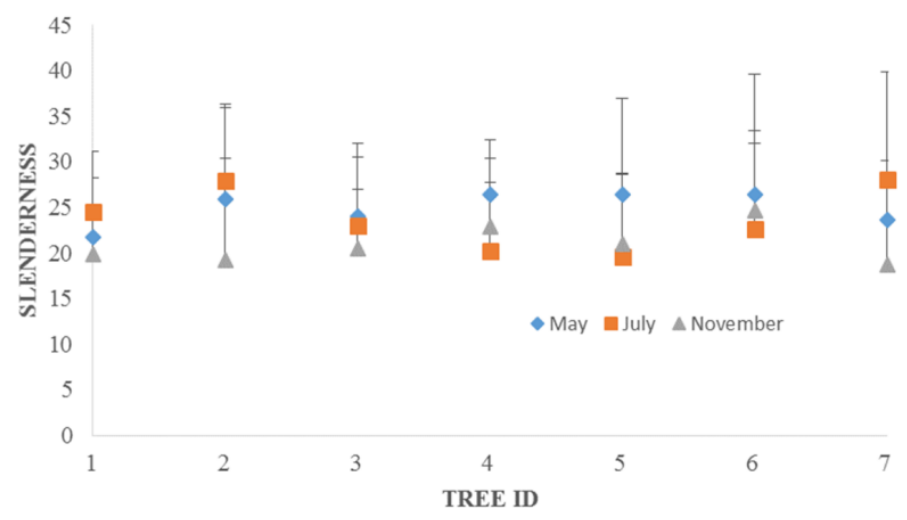

Figure 3. Dynamics of branch slenderness for each tree (vertical lines indicate standard deviation)
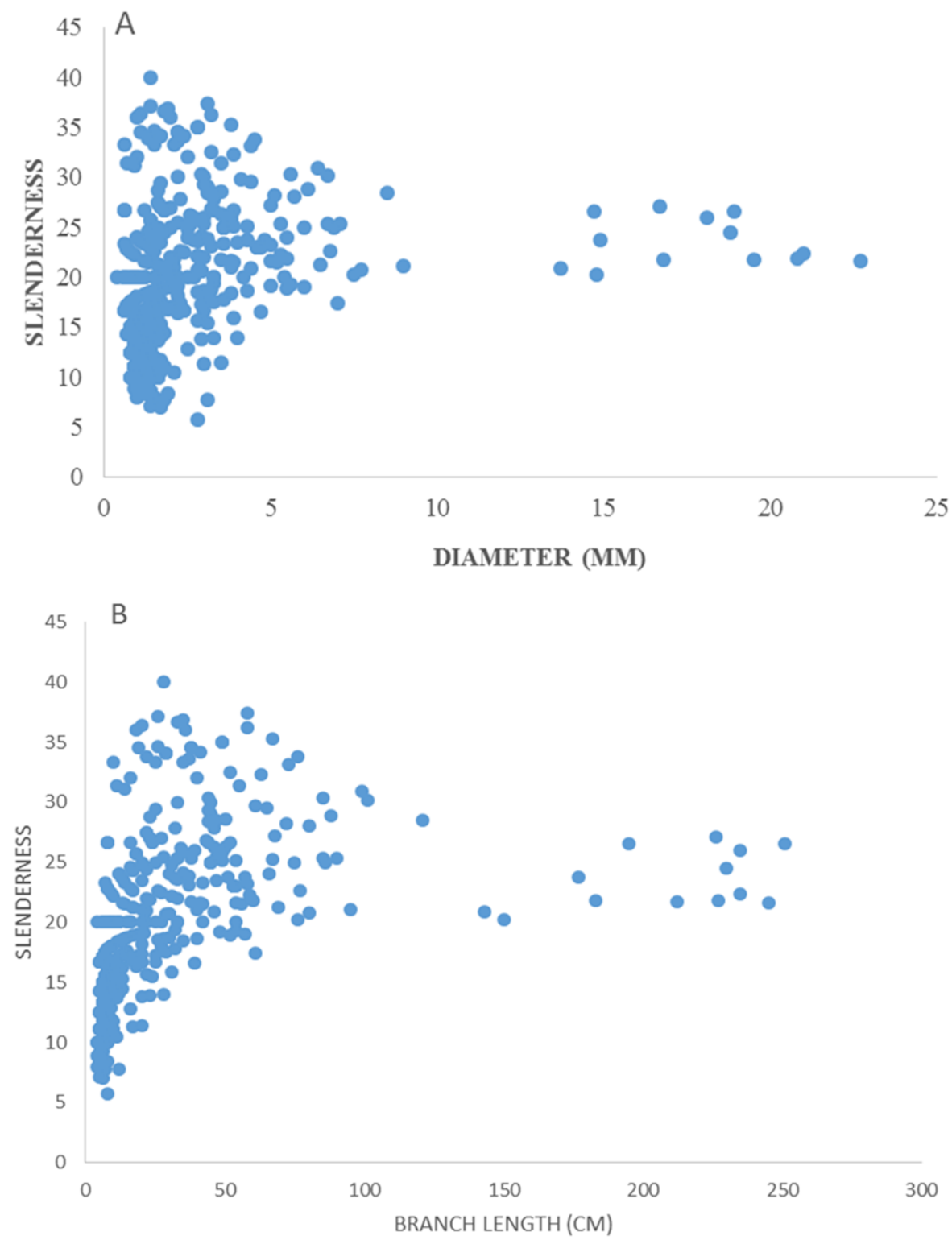

Figure 4. Slenderness changed with branch diameter (A) and length (B). 
The scaling between branch radius and length $(\log R-\log L)$ indicated that the scaling exponents were concentrated around $1.0(p<0.05)$ (Table 4), but for some trees (such as for Tree 2 and 5 ) the exponents changed significantly with branch growth $(p<0.05)$.

Table 4. Scaling exponents between branch radius and length for each tree along time (The correlations were significant at $\alpha<0.05$ for all except for the indicated ones by $£$ )

\begin{tabular}{|c|c|c|c|c|c|c|}
\hline \multirow[t]{2}{*}{ Tree ID } & \multicolumn{2}{|c|}{ May, 2016} & \multicolumn{2}{|l|}{ July, 2016} & \multicolumn{2}{|c|}{ November, 2016} \\
\hline & Exponent & $R^{2}$ & Exponent & $R^{2}$ & Exponent & $R^{2}$ \\
\hline 1 & 0.88 & 0.6693 & 1.01 & 0.8083 & 1.15 & 0.6984 \\
\hline 2 & $0.73^{\mathfrak{f}}$ & 0.5863 & 1.02 & 0.8056 & 1.05 & 0.8278 \\
\hline 3 & 1.01 & 0.7158 & 1.13 & 0.8202 & 1.09 & 0.8773 \\
\hline 4 & 0.94 & 0.7793 & 1.05 & 0.7298 & 0.99 & 0.7957 \\
\hline 5 & $0.77^{\mathfrak{f}}$ & 0.5405 & 0.98 & 0.6613 & 1.21 & 0.8553 \\
\hline 6 & 0.82 & 0.6992 & 0.93 & 0.7412 & 1.12 & 0.8342 \\
\hline 7 & 1.02 & 0.6335 & 0.92 & 0.7499 & 1.16 & 0.8387 \\
\hline
\end{tabular}

The correlation between the branch diameters of $1^{\text {st }}$ order and the branch number of $2^{\text {nd }}$ order was not significant, such as for Tree 1 (Fig. 5A). Same as the correlation between the branch diameters of $1^{\text {st }}$ order and the branch number at all next orders, such as for Tree 1 (Fig. 5B). The correlation between the branch length of the $1^{\text {st }}$ order and the number of branches at all next orders was also not significant (Fig. 5C). This means that the large branches did not necessary have more branches at the next lower orders. 
A
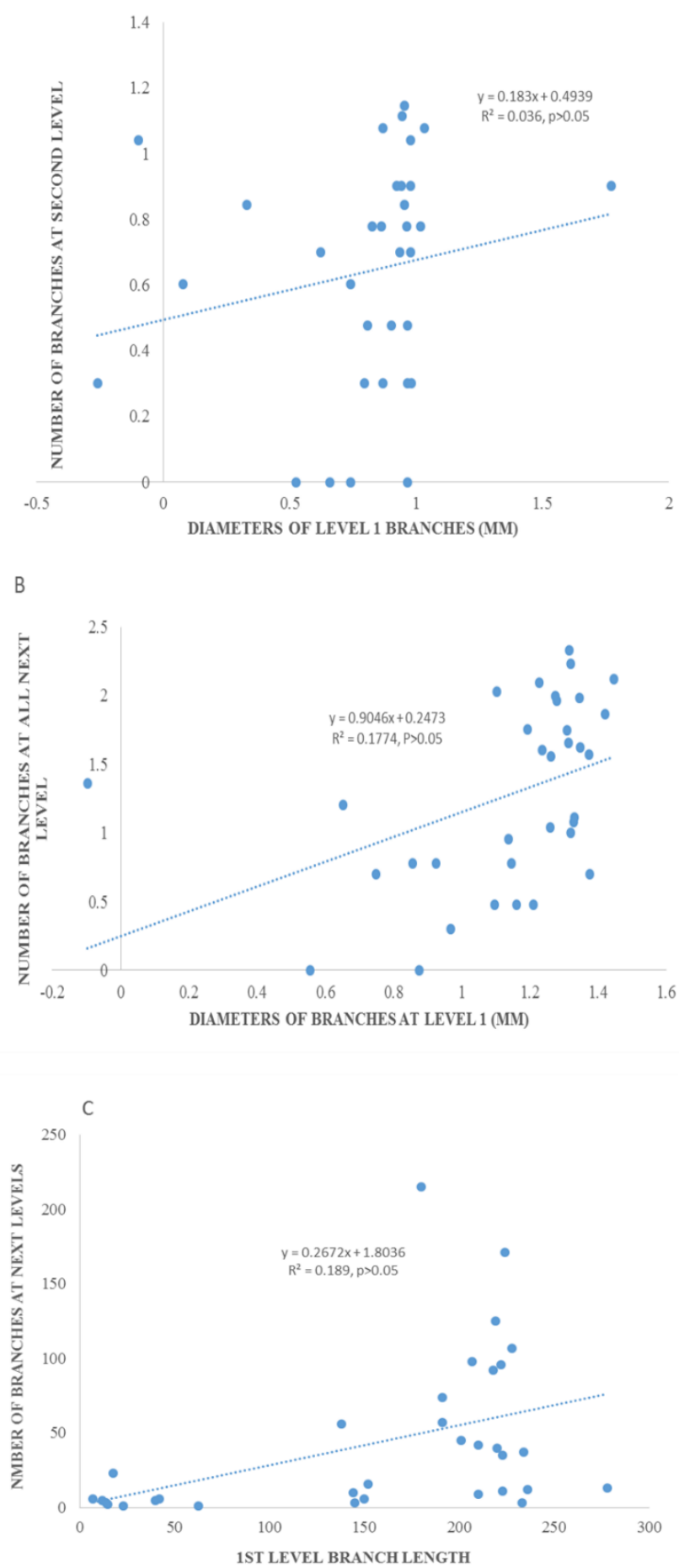

Figure 5. Correlation between the branch diameters of $1^{\text {st }}$ level (order) and the branch number at $2^{\text {nd }}$ level (A), and the branch number at all next levels (B); the correlation between the branch lengths of $1^{\text {st }}$ level and the branch number at all next levels $(\mathrm{C})$

\section{Discussion}

The pipe model theory assumed that the cross-section areas in branches should be equal to stem areas of a tree (Shinozaki et al., 1964), which means the basal area of branches at one level (order) should be equal to the branch basal area at the next level (order). The results in this study did not support this assumption. Mäkelä 
(2002) suggested that the pipe model theory should be modified to include the transitional, inactive sapwood zone because active pipes may not always be identified with the entire sapwood area. The dependence of pipe model may also be affected by numerous other factors such as site, stand closure, and social class of the tree position in the stand (Whitehead, 1978; Thompson, 1989).

It was expected that the distribution of branches in each individual tree would follow a similar power law because the branches are connected as a network. Tree branches, like other networks in nature, are considered to follow a similar power law with a fixed scaling exponent (e.g., 3/4) (Brown et al., 2002). It was found in this study that the scaling exponents of frequency distribution for both branch length and diameter changed with time in seven trees. Differences also existed among individual trees. The scaling exponents were not a fixed number. This was supported by the previous result (e.g., Chen \& Burton, 2010). This study showed the dynamics of the scaling exponents within one growing season.

Entropy is used to reflect the information on branch length and diameter. The entropy was very consistent for branch length and diameter among trees. This means that these tree branches were very well organized networks. Also there were dynamics in entropy during tree growth. The decreased entropy in July might be related to quick growth during the summer time or some branches were broken down during measuring. The increased entropy in November indicated tree canopy is a self-organized network. However, at the end of the growing season of 2016, the entropy of neither branch length nor diameter reached the maximum entropy (MaxEnt). The MaxEnt could overestimate the information entropy in ecological systems (Chen et al., 2016). Previous studies found that MaxEnt is not correct when characterizing the size-density relationship and intraspecific distribution of body size (Xiao et al., 2015). It is possible that a tree's canopy may not reach the MaxEnt status in its branch distribution.

Slenderness could be used to characterize a branch's form. The change in slenderness reflected the relative growth rate of length to radius. In this study, the average slenderness for branches of seven trees was about 20, but some trees could reach a slenderness of 28 during their growth. There existed high variations within small branches which were less than $10 \mathrm{~mm}$ in diameter or less than $100 \mathrm{~cm}$ in length. These numbers may be unique to crape myrtle, because other tree species could reach a slenderness around 260 (Bertram, 1989). Dahle \& Grabosky (2010) found that slenderness of Acer platanoides L. (Norway maple) peaked near 300 and appeared to shift at the branch length of $300 \mathrm{~cm}$. These thresholds might mean that branches approach potential instability when they were transitioning from a primary role of flexible branch to a stiffer structural branch. Quantifying slenderness may be a useful tool in predicting branch form and instability.

For the scaling relationship between branch length and diameter, the results from this study showed that the scaling exponents were close to 0.67 for some individual trees (Tree 2, 5 and 6) in May, but the scaling exponents were close to 1.0 in July and November. This means that the branches of crape myrtle followed the geometric similarity model most of the time. McMahon \& Kronauer (1976) studied several whole tree crowns and concluded that branch length scales as 0.67 , as predicted by their elastic similarity model. The elastic similarity model simulates branch growth through the process of secondary growth, not primary growth (Niklas, 1994). The scaling exponents could change for individual trees at same location within a growing season. Although the scaling exponent has been assumed to be constant within an individual (Mäkelä, 1986) or even for different tree species (Enquist et al., 1999), it may vary to reflect the different stages in growth of branches (Bertram, 1989).

Allometric scaling was also related to the correlation between the diameters of $1^{\text {st }}$ order branches and the number of branches at the $2^{\text {nd }}$ order or next orders. The change in the relationship could affect energy investment in branch elongation. In this study the results indicated that the large branches of crape myrtle did not necessary have more branches at next lower orders. But for another species, Norway maple, a significant quadratic regression existed between the number of 2nd order and the 1st order branch length (Dahle \& Grabosky, 2010). This indicates that when primary branch length slows, investment of photosynthetic product in elongation would likely turn towards the lateral branches.

In conclusion, after studying the allometric properties of branches in crape myrtle during one growing season, there were some general trends in dynamics (e.g., entropy and scaling exponents) but divergence also existed in allometric scaling relationships for each tree and among trees. Any fixed number in allometric scaling exponents may not reflect the real situation. The knowledge from this study may help to understand the dynamics of branch development in crape myrtles to form canopy in individual trees.

\section{Acknowledgements}

The author is thankful to Matthew Shaw, Lawson Quick, and Michael Brown for assisting in field work. This 
study was supported by USDA National Institute of Food and Agriculture McIntire Stennis project (1008643).

\section{References}

Bertram, J. E. A. (1989). Size-dependent differential scaling in branches: the mechanics design of trees revisited. Trees, 4, 241-253. https://doi.org/10.1007/BF00225358

Brown, J. H., Gupta, V. K., Li, B. L., Milne, B. T., Restrepo, C., \& West, G. B. (2002). The fractal nature of nature: power laws, ecological complexity and biodiversity. Philosophical Transactions of the Royal Society of London B Biological Science, 357, 619-626. https://doi.org/10.1098/rstb.2001.0993

Chen, X., \& Burton, S. (2010). Power law relationships in the branches of loblolly pine, red maple and sugar maple trees. Dendrobiology, 63, 3-9.

Chen, X., Brockway, G. D., \& Guo, Q. (2016). Entropy dynamics in cone production of logleaf pine forests in the southeastern United States. Mathematical and Computational Forestry \& Natural-Resource Sciences, 8, $11-15$.

Dahle, G. A., \& Grabosky, J. C. (2010). Allometric patterns in Acer platanoides (Aceraceae) branches. Trees, 24, 321-326. https://doi.org/10.1007/s00468-009-0401-5

Enquist, B. J, West, G. B., Charnov, E. L., \& Brown, J. H. (1999). Allometric scaling of production and life-history variation in vascular plants. Nature, 88, 907-911. https://doi.org/10. 1038/44819

Harte, J. (2011). Maximum entropy and ecology: a theory of abundance, distribution, and energetics. Oxford University Press, Oxford.

Jaynes, E. T. (1957). Information theory and statistical mechanics. Physical Review, 106, 620-630. https://doi.org/10.1103/PhysRev.106.620

King, D. A. (1986). Tree form, height growth, and susceptibility to wind damage in Acer saccharum. Ecology, 67, 980-990. https://doi.org/10.2307/1939821

Küppers, M. (1989). Ecological significance of above ground architectural patterns in woody plants: a question of cost-benefit relationships. Trends in Ecology and Evolution, 4, 375-379. https://doi.org/10.1016/0169-5347(89)90103-1

Mäkelä, A. (1986). Implications of the pipe model theory on dry matter partitioning and height growth in trees. Journal of Theoretical Biology, 123, 103-120. https://doi.org/10.1016/S0022-5193(86)80238-7

Mäkelä, A. (2002). Derivation of stem taper from the pipe theory in a carbon balance framework. Tree Physiology, 22, 891-905. https://doi.org/10.1093/treephys/22.13.891

Mandelbrot, B. B. (1978). The fractal geometry of trees and other natural phenomena. P. 235-249. In: Miles, R. E., J. Serra (eds). Geometrical probability and biological structures: Buffon's 200th anniversary. Springer, Berlin.

McMahon, T. A., \& Kronauer, R. E. (1976). Tree structures: deducing the principle of mechanical design. Journal of Theoretical Biology, 59, 443-466. https://doi.org/10.1016/0022-5193(76)90182-X

Niklas, K. J. (1995). Size-dependent allometry of tree height, diameter and trunk-taper. Annals of Botany, 75, 217-227. https://doi.org/10.1006/anbo.1995.1015

Niklas, K. J., \& Spatz, H. C. (2000). Wind-induced stresses in cherry trees: evidence against the hypothesis of constant stress levels. Trees, 14, 230-237. https://doi.org/10.1007/s004680050008

Nishimura, T. B. (2005). Tree characteristics related to stem breakage of Picea glehnii and Abies sachalinensis. Forest Ecology and Management, 215, 295-306. https://doi.org/10.1016/j.foreco.2005.05.018

Osunkoya, O. O., Omar-Ali, K., Amit, N., Dayan, J., Daud, D. S., \& Sheng. T. K. (2007). Comparative height-crown allometry and mechanical design in 22 tree species of Kuala Belalong rainforest, Brunei, Borneo. American Journal of Botany, 94, 1951-1962. https://doi.org/10.3732/ajb.94.12.1951

Raulier, F., Ung, C-H., \& Ouellet, D. (1996). Influence of social status on crown geometry and volume increment in regular and irregular black spruce stands. Canadian Journal of Forest Research, 26, 1742-1753. https://doi.org/10.1139/x26-198

Remphrey, W. R., \& Davidson, C. G. (1992). Branch architecture and its relation to shoot-tip abortion in mature Fraxinus pennsylvanica. Canadian Journal of Botany, 70, 1147-1153. https://doi.org/10.1139/b92-142

Remphrey, W. R., \& Powell, G. R. (1984). Crown architecture of Larix laricina saplings: quantitative analysis 
and modelling of (nonsylleptic) order 1 branching in relation to development of the main stem. Canadian Journal of Botany, 62, 1904-1915. https://doi.org/10.1139/b84-260

Richter, J. P. (1970). The notebooks of Leonardo da Vinci. Dover Publications, Dover.

Shinozaki, K., Yoda, K., Hozumi, K., \& Kira, T. (1964). A quantitative analysis of plant form. Pipe model theory. I. Basic analysis. Japanese Journal of Ecology, 14, 97-105.

Skatter, S., \& Kucera, B. (2000). Tree breakage from torsional wind loading due to crown asymmetry. Forest Ecology and Management, 135, 97-103. https://doi.org/10.1016/S0378-1127(00)00301-7

Sperry, J. S., Meinzer, F. C., \& McCulloh, K. A. (2008). Safety and efficiency conflicts in hydraulic architecture: scaling from tissues to trees. Plant, Cell and Environment, 31, 632-645. https://doi.org/10.1111/j.1365-3040.2007.01765.x

Takenaka, A. (2000). Responses to light microenvironment and correlative inhibition in the growth of shoots of tree seedlings under a forest canopy. Tree Physiology, 20, 987-991. https://doi.org/10.1093/treephys/20.14.987

Taugourdeau, O., Dauzat, J., Griffon, S., Sabatier, S., Caraglio, Y., \& Barthe'le'my, D. (2012). Retrospective analysis of tree architecture in silver fir (Abies alba Mill.): ontogenetic trends and responses to environmental variability. Annals of Forest Science, 69, 713-721. https://doi.org/10.1007/s13595-012-0188-1

Thompson, D. C. (1989). The effect of stand structure and stand density on the leaf area - sapwood area relationship of lodge pole pine. Canadian Journal of Forest Research, 19, 392-396. https://doi.org/10.1139/x89-061

West, G. B., Brown, J. H., \& Enquist, B. J. (1999). A general model for the structure and allometry of plant vascular systems. Nature, 400, 664-667. https://doi.org/10.1038/23251

White, E. P., Enquist, B. J., \& Green, J. L. (2008). On estimating the exponent of power-law frequency distributions. Ecology, 89, 905-912. https://doi.org/10.1890/07-1288.1

Whitehead, D. (1978). The estimation of foliage area from sapwood basal area in Scots pine. Forestry, 51, 137-149. https://doi.org/10.1093/forestry/51.2.137

Xiao, X., McGlinn D. J., \& White, E. P. (2015). A strong test of the maximum entropy theory of ecology. American Naturalist, 185, E70-E80. https://doi.org/10.1086/679576

\section{Copyrights}

Copyright for this article is retained by the author(s), with first publication rights granted to the journal.

This is an open-access article distributed under the terms and conditions of the Creative Commons Attribution license (http://creativecommons.org/licenses/by/4.0/). 